\title{
Thermomechanical Treatment Influence on the High-speed Steel Hardness and Wear
}

\author{
Dorin Catana \\ Faculty of Materials Science and Engineering, Transilvania University of Brasov, Romania
}

Copyright (C) 2015 by authors, all rights reserved. Authors agree that this article remains permanently open access under the terms of the Creative Commons Attribution License 4.0 International License.

\begin{abstract}
Thermomechanical treatment consists in using two classic manufacturing methods. This type of treatment was applied to studied high-speed steel (HS2-9-1-8). The tests performed aimed to establish the influence on the hardness and wear of the high-temperature thermomechanical treatment (HTTMT) applied to studied steel. The application of an additional plastic deformation (the deformation degree between 45 - 75\%) positively influences the hardness and wear value. Being a HTTMT, the plastic deformation was followed by quenching, the utilized agent being the oil or compressed air. When the quenching agent was the oil the hardness increased by $6-7 \%$ and the wear diminished up to $40 \%$. Samples thermally treated in the classical way were used as comparison elements. The study performed shows that a favourable evolution of the analysed properties appears when the deformation degree is between 55 and $75 \%$. The air compressed quenching sets for the analysed characteristics, the same evolution with those obtained during the oil quenching. The increased hardness for the studied high-speed steel utilized at cutting tools manufacturing will generate a slower wear of the cutting edge that means important economies in cutting process.
\end{abstract}

Keywords High-speed Steel, Thermomechanical Treatment, Hardness, Wear

\section{Introduction}

In general, most pieces executed for the industry are of the metallic materials, being processed by cutting; therefore the consumption of cutting tools is significant. Although the materials for cutting-tool manufacturing are more and more diversified, their range being in a permanent extension, the old materials have not been utterly abandoned, but their role has only diminished. Nowadays, the tools obtained by physical vapour-deposit methods (PVD) represent more than $50 \%$ of the overall cutting tool consumption and are likely to go beyond. Thanks to an acceptable price/quality ratio and to good toughness (resilience), the high-speed steel tools will be especially used for processing unique pieces. This is the reason why this research has been launched. Establishing the connections between the properties of the cutting tool material and its technical performances is one of the main practical problems that must be solved and which, in the current stage of the processing industry, are of the major importance. One also, attempts to improve the cutting tools properties, by combining or applying new material processing methods. Recognizing the role, diversity and major importance of the cutting tools, any effort made for improving their reliability is justified.

An ideal cutting tool should have high hardness and toughness. The actual cutting tools have great hardness, property which can be also provided by high-speed steels; however, many times their toughness is often low. Previous researches have shown that applying a thermomechanical treatment (heat plastic deformation followed by thermal treatment specific to high-speed steel) improves both hardness and toughness Catana[1]. Another test has been made on two wolfram-molybdenum high-speed steels and the conclusion was to use tools made by plastic deformation Berkowski[2].

The research program was developed in three stages. In the first stage, certain mechanical and technological characteristics of the studied deformed steel were determined. During the second stage, the influence of the thermomechanical treatment applied to the HS2-9-1-8 high-speed steel on its hardness and wear was studied. In the last stage, still in progress, the behaviour in the cutting process of the tools made of the studied steel, thermo-mechanically treated, is analyzed. This paper presents the results of the second stage and shows a way to improve, material hardness and wear, which obviously will increase the characteristics of cutting tool.

\section{Theoretical Considerations}

The mechanical resistance of the metallic materials can be increased on two diametrically opposed ways: achieving an ideal structure without faults, which requires special 
technical conditions or creating faults (especially dislocations) and limiting their displacement - an industrially-achievable solution. The second method, which is more easily to apply from technological point of view, is based on plastic deformation processes and thermal treatments. The mentioned processes may be separately applied or a thermomechanical treatment may be applied, which will enhance simultaneously and/or successively the two processes. The described study, was performed on HS2-9-1-8 high-speed steel, used for manufacturing cutting tools with high diameters and complex geometry (category of the bore disk milling cutter) for which the plastic deformation through pressing is adequate Micu[3]. The chemical composition of the high-speed steel being tested and that of the equivalent steels is shown in Table 1. This steel was chosen because the high percentage of Co $(8 \%)$ determines the rising of the material heat resistance, characteristic for the cutting, at high speeds.

Table 1. High-speed steel chemical composition

\begin{tabular}{|c|c|c|c|c|c|c|}
\hline \multirow{2}{*}{$\begin{array}{c}\text { High-speed } \\
\text { steel type }\end{array}$} & \multicolumn{5}{|c|}{ Chemical composition (average values in \%) } \\
\cline { 2 - 7 } & $\mathrm{C}$ & $\mathrm{Cr}$ & $\mathrm{Mo}$ & $\mathrm{W}$ & $\mathrm{Co}$ & $\mathrm{V}$ \\
\hline $\mathrm{M} 42$ & 1.1 & 3.8 & 9.5 & 1.5 & 8 & 1.2 \\
\hline HS2-9-1-8 & $1.05-1.15$ & $3.5-4.5$ & $9-10$ & $1.2-1.9$ & $7.5-8.5$ & $0.9-1.3$ \\
\hline S500 & 1.10 & 3.9 & 9.2 & 1.4 & 8.0 & 1.2 \\
\hline
\end{tabular}

The general purpose of the thermomechanical treatment consists in obtaining optimal associations of mechanical properties (high hardness and plasticity, low wear), different from those determined by the classical thermal treatments. High temperature thermomechanical treatment (HTTMT) can be used for processing tools and other high-speed steel components of simple geometrical shapes Dobrzanski[4]. Applying thermomechanical treatments, the resistance properties increase simultaneously maintaining the good values of plasticity, when the deformation degree is between $40-50 \%$ Popescu[5]. If deformation occurs through forging, the resilience has maximal values for a deformation degree of $60-80 \%$. In the case of other high-speed steels, improved characteristics of the hardness, moment-resistance and resilience were obtained, for deformation degrees of $45-85 \%$ Catana [1].

The thermomechanical treatment applied to the studied steel is one of high temperature, which means that the plastic deformation was made at temperatures above re-crystallization temperature $\left(950-980^{\circ} \mathrm{C}\right)$, followed by quenching and high tempering.

The high-temperature thermomechanical treatment applied to the HS2-9-1-8 high-speed steel was performed in the following way:

- heating at $1200-1230^{\circ} \mathrm{C}$;

- plastic deformation through hammer forging with deformation degrees ranging between $50-70 \%$ up to temperature $1000-980^{\circ} \mathrm{C}$; the applied deformation degree being high, for some samples there was necessary to stop the plastic deformation, re-heat the samples and resume the process of plastic deformation;

- oil or compressed air (5 bars pressure) quenching.

The process continued with three high tempering (heating at $530-540^{\circ} \mathrm{C}$ ), to remove the residual austenite. The deformation degree was calculated by using (1) Adrian[6]:

$$
\varepsilon=\frac{h_{i}-h_{f}}{h_{i}} \cdot 100,
$$

where: $\varepsilon$ is deformation degree, $h_{i}$ is initial height [mm] and $h_{f}$ is final height $[\mathrm{mm}]$. The pressing deformation degree was calculated based on the height, as the measuring precision is greater than in the case of diameter measuring.

Analysing the influence of the thermomechanical treatment on the hardness and wear, one concluded that a deformation degree less than $50 \%$ did not result in positive evolutions of the studied properties.

The figure 1 shows a comparison between the HS2-9-1-8 high-speed steel microstructures for various plastic deformation degree (nital attack reagent, $100 \mathrm{x}$ enlargement). The sample deformed with $\varepsilon=70 \%$ has the best microstructure because the constituents repartition is uniform; structure is very fine and, probably provides the best mechanical properties.

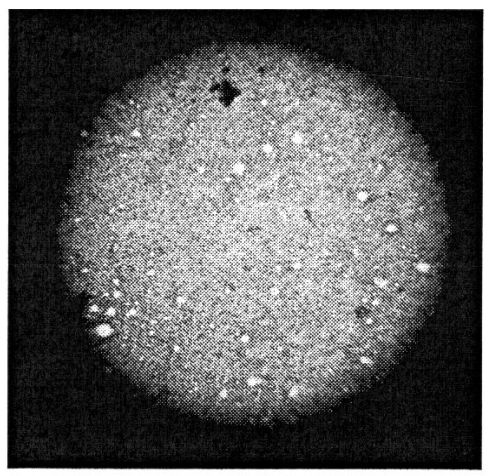

a)

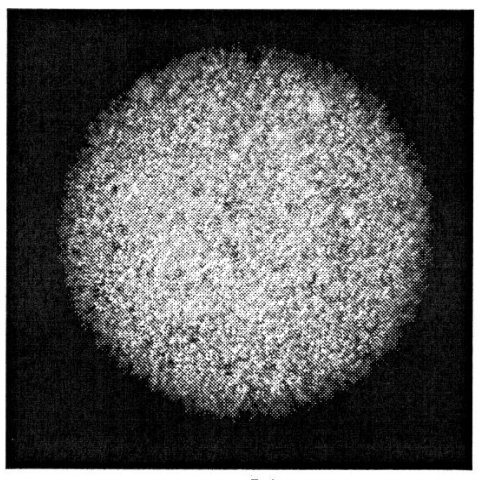

b)

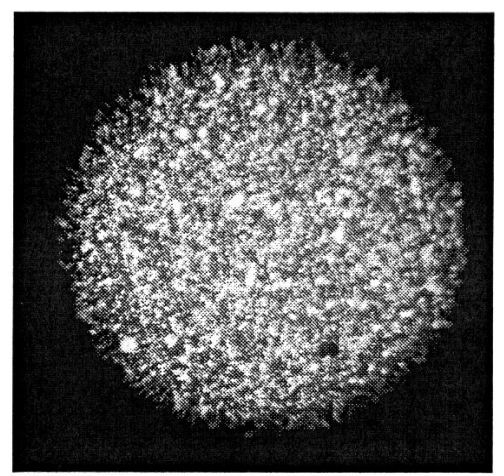

c)

Figure 1. Microstructure of plastic deformed HS2-9-1-8 steel: $\varepsilon=0 \%$ (a), $\varepsilon=50 \%$ (b), $\varepsilon=70 \%$ (c) 


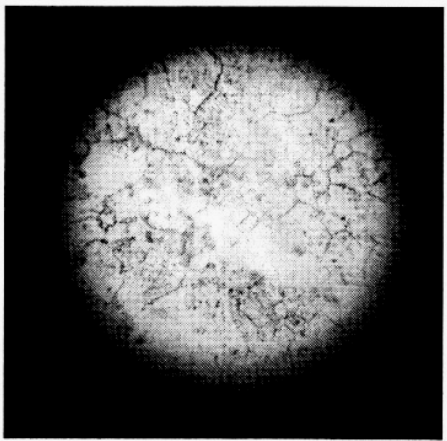

a)

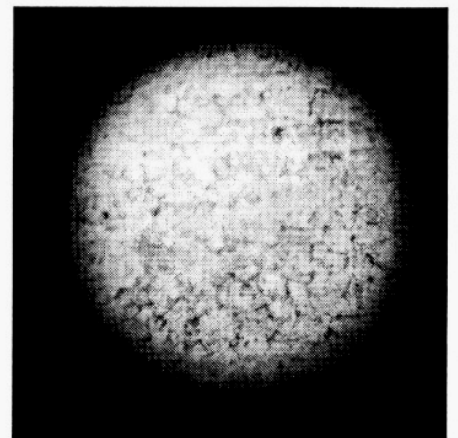

b)

Figure 2. Microstructure of the thermomechanical treatment HS2-9-1-8 steel: $\varepsilon=60 \%$ (a), $\varepsilon=70 \%$ (b)

The thermomechanical treatment continued with an oil quenching (oil temperature $100^{\circ} \mathrm{C}$ ), which maintained the positive evolution of the microstructure (Murakami attack reagent, $400 \mathrm{x}$ enlargement). For $\varepsilon=70 \%$ one observed the carbides with small dimensions (dark colour area) and their uniform distribution. The $\varepsilon=70 \%$ microstructure is better than $\varepsilon=60 \%$ and obviously better than $\varepsilon=0 \%$ (see figure 2 ).

\section{Experimental Results}

The tests were performed on cylindrical samples of HS2-9-1-8 high-speed steel with the initial diameter of 25 $\mathrm{mm}$ and the initial height of $40 \mathrm{~mm}$. These samples were pressed through forging with various deformation degrees. The deformation degree was calculated with (1). Applying HTTMT determines significantly improvement of the HS2-9-1-8 high-speed steel micro-structure compared to the samples that have not benefited from plastic deformation. For the thermo-mechanically treated samples and oil or air quenched samples, the hardness was measured.

The hardness increase is above $7 \%$ for the samples whose deformation degree was of $70 \%$, as compared to the hardness of the samples that were not plastically deformed $(\varepsilon=0 \%)$, but treated by the oil quenching and high tempering only (see figure 3 ).

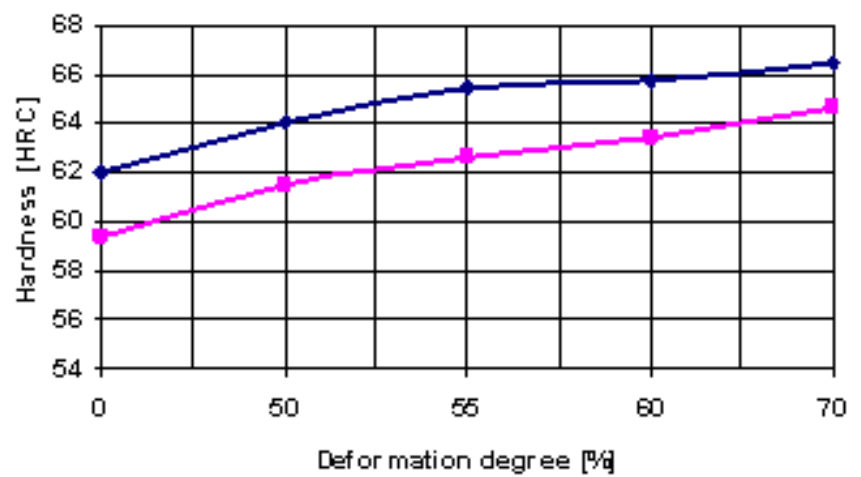

$\longrightarrow$ - al quenching $\longrightarrow$ Air quenching

Figure 3. Hardness evolution of the thermo-mechanically treated and oil or compressed air quenched HS2-9- 1-8 steel, depending of the deformation degree
Likewise, for deformation degrees of 50-60\%, a hardness increase it was noticed. The hardness increasing being of a few units HRC, its influence on the behaviour at wear of the samples was also verified. The similar evolution of the hardness is noticed for the air quenching.

The wear was determined with a device Olah[7] that allows simultaneous test of two samples: a sample is set in the support of a rotating shaft and another one in an axially shifting support (see figure 4).

The wear test was made with device shown in figure 4 that allows a wear test of the whole surface of the sample. This is necessary because, in the cutting process, both the edges and surfaces of the cutting tool are affected by wears. The surfaces of the samples are in permanent contact due to the coil spring included in the device, through which the pressing force is applied. After every test interval (30 minutes), the samples have changed places: the sample of rotating shaft was moved to the axial displacement support and conversely. The same wear conditions were ensured for all the samples. The testing conditions were: rotation speed of the shaft $880 \mathrm{rpm}$, pressing force of the samples $300 \mathrm{MPa}$ and test time 30 minutes. For a more accentuated wear, the test was made without cooling and without lubricating the surfaces. The temperature reached by the samples at the end of the test interval was of $110-130^{\circ} \mathrm{C}$, lower as compared to the temperatures developed by the cutting tools of high-speed steels during the cutting operations.

The wear was determined based on the sample mass loss during the tests, these being weighed before and after the test with a 4-decimal electronic scale (Kern ALS 120-4). The wear was determined with (2):

$$
w=\frac{m_{i}-m_{f}}{m_{i}} \cdot 100,
$$

where $w$ is wear, $m_{i}$ initial mass of the sample and $m_{f}$ sample mass after test (after 30 minutes). After each test, for a better accuracy of the results, all the samples were cleaned in an ultrasonic bath of alcohol before weighed Wang[8]. 


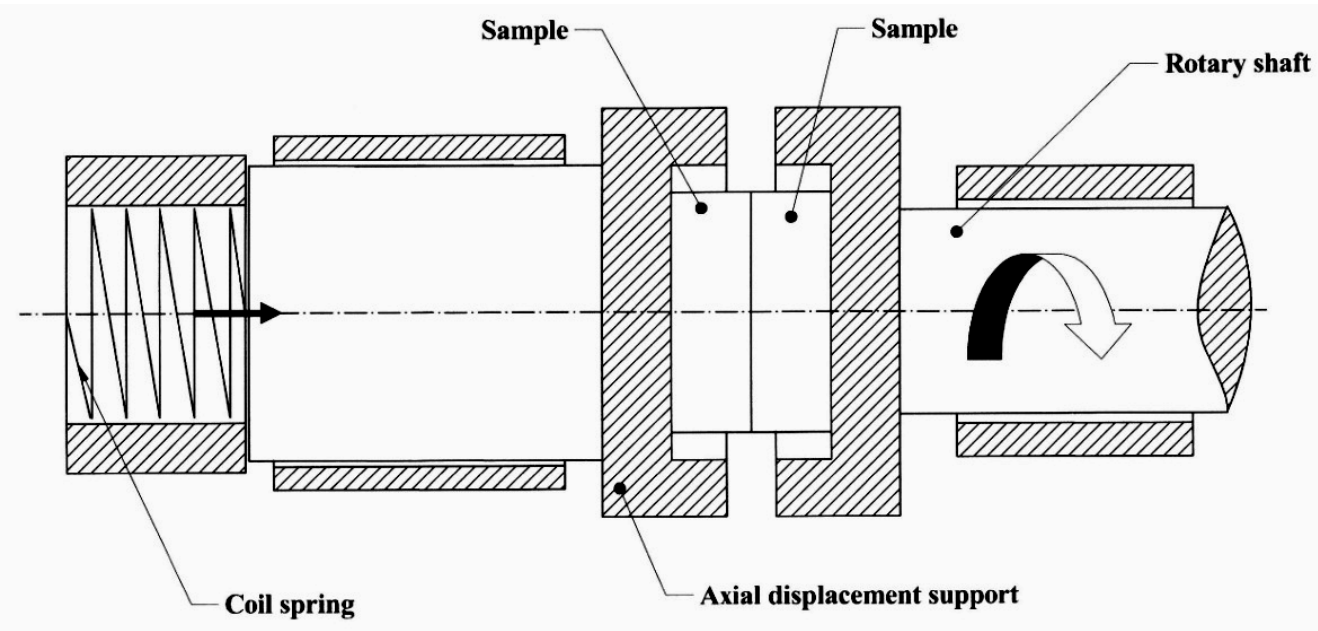

Figure 4. Wear testing device

In figure 5, the evolution in time of the wear, for the thermo-mechanically treated and oil-quenched samples of HS2-9-1-8 high-speed steel is shown. The total sample-testing time was of 180 minutes, the samples being weighed at 30-minute intervals. The figure 5 shows that the thermomechanical treatment in oil quenching applied to the HS2-9-1-8 high-speed steel had as result a lower wear of the plastic deformed samples than in case of those not having been plastically deformed.

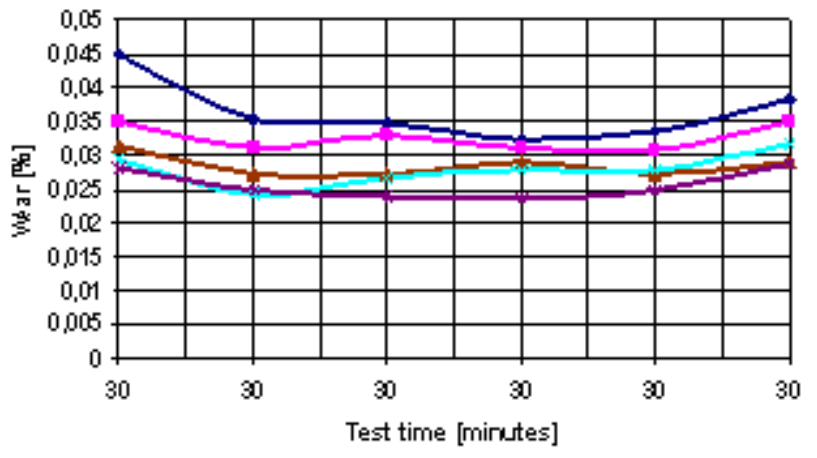

$\rightarrow-0 \%=-50 \%-55 \%=60 \%=70 \%$

Figure 5. Evolution in time of the wear, for the HS2-9-1-8 thermo-mechanically treated and oil quenched steel

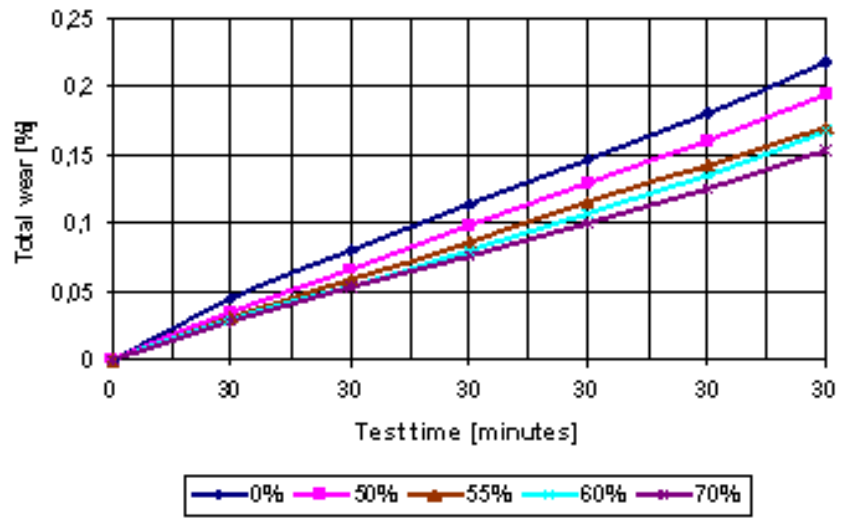

Figure 6. Evolution of the overall wear in time, for the HS2-9-1-8 thermomechanical treated steel and oil quenched
In figure 6, the wear evolution of the thermo-mechanically treated HS2-9-1-8 steel as compared to the beginning of the test is shown; the graph better shows the differences between the wears of the thermo-mechanically treated samples and those not having undergone the respective treatment. In the case of the HS2-9-1-8 thermo-mechanically treated and compressed air quenched steel, the evolution of the wear is shown in figure 7.

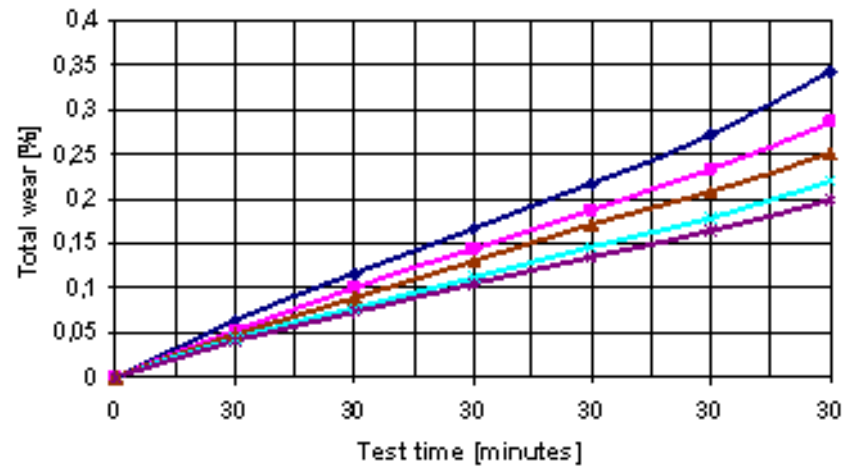

$$
\text { - } 0 \text { 0\% }=50 \% \div-55 \% \div 60 \% \div-70 \%
$$

Figure 7. Evolution of the overall wear in time, for the HS2-9-1-8 thermomechanical treated steel and compressed air quenched

\section{Conclusions}

Applying the high-temperature thermomechanical treatment (HTTMT), to the HS2-9-1-8 high-speed steel favourably influences the hardness and wear of the respective steel. In the case of the thermo-mechanically treated and oil quenched samples, the increase is of $7 \%$ for a deformation degree of $70 \%$, as compared to those not having been deformed. For deformation degrees ranging between $50 \%$ and $60 \%$, there are also hardness increases following the application of HTTMT, but with a smaller percentage. In terms of wear, figure 5 shows that the 
smallest wear is for the samples whose deformation degree was of $70 \%$. The wear evolution is similar both for the thermo-mechanically treated samples and for the non-deformed ones. After a more accentuated wear at the beginning of the test due to running in, the wear remained almost constant during the test.

Analyzing figure 6, the evolution of the wear on the entire test may be better noticed. After 180-minute test, the thermo-mechanically treated samples display much lower wears than those not have been deformed. For a deformation degree of $70 \%$, applied during HTTMT, the material wear is much lower (42\%), than that of the non-deformed material $(\varepsilon=0 \%)$, the same favourable evolutions being registered in the case of the 50,55 and $60 \%$ plastic deformed samples. The studied characteristics for the thermo-mechanically treated HS2-9-1-8 steel are significantly improved for the deformation degrees ranging between 60 and $70 \%$. Although the hardness did not significantly increase (7\%), the impact on the wear is much more relevant, its diminution being of $42 \%$. The compressed air quenching of the thermo-mechanically treated HS2-9-1-8 steel results in a same positive evolution of the wear. More exactly, the wear of the HS2-9-1-8 steel is much lower, with $75 \%$ (figure 7), as compared to the non-deformed material, the same favourable evolution being registered for various plastic deformation degrees applied. In the case of compressed air quenching, the hardness increasing is over $8 \%$, for the samples that were deformed with a deformation degree of $70 \%$.

Applying the high-temperature thermomechanical treatment to the HS2-9-1-8 steel has as result a hardness increasing and a wear reduction, with implications in the increasing of the metal cutting productivity (the re-dressing being necessary less frequently) and in reducing the processing cost (lower cutting-tool consumption).

\section{REFERENCES}

[1] D. Catana, D. A. Catana. Thermo-mechanic treatment influence on microstructure and mechanical properties of high-speed steel, Metalurgia International, Volume XV, No. 9, 44-46, 2010.

[2] L. Berkowski. The influence of warm plastic deformation on the structure and on the applicable properties of high-speed steel, Journal of Materials Processing Technology, Volume 60, No. 1-4, 637-641, 1996.

[3] D-A. Micu. Contribution and researchers regarding the application on the thermo-mechanical treatments on the tools steels and their implication for work safety and health of the operator, Ph. D. Thesis, University Transilvania of Brasov, Brasov, 2010.

[4] L. A. Dobrzanski. High temperature thermo-mechanical treatment of 12-0-2-C type high-speed steel, Journal of Materials Processing Technology, Volume 38, No. 1-2, 123-133, 1993.

[5] N. Popescu, C. Gheorghe, O. Popescu. Unconventional heat treatments, Technique Publishing, Bucharest, 1990.

[6] M. Adrian, S. Badea.Plastic deformation process fundamentals, Technique Publishing, Bucharest, 1983.

[7] A. Olah, Tierean, M. H. Tierean. Research about influence of nitro carburizing on metal coating layers, Metalurgia International, Volume XVI, No. 5, 149-152, 2011.

[8] Q. Wang, C. Huang, L. Zhang. Microstructure and tribological properties of plasma nitriding cast CoCrMo alloy, Journal of Materials Science \& Technology, Vol. 28, No. 1, 60-66, 2012. 